\title{
Hyaluronic acid in calves defects correction
}

\author{
Lorenzo Rosset ${ }^{1}$, Mario Goisis ${ }^{2}$ \\ ${ }^{1}$ School of Medicine, University of Turin, 10043 Orbassano, Italy. \\ ${ }^{2}$ Doctor's Equipe, via Carducci 19, 20123 Milan, Italy.
}

Address for correspondence: Mr. Lorenzo Rosset, School of Medicine, University of Turin, San Luigi Gonzaga, Regione Gonzole 10, 10043 Orbassano, Italy. E-mail: lorenzo_rosset@yahoo.it

\begin{abstract}
Aim: Since the advent of fillers, new techniques are continuously developed for different uses. In this study, we evaluated the use of hyaluronic acid for calf augmentation. Methods: A total of 42 patients were enrolled in this study. All of them underwent augmentation procedure in our centers under local anesthesia, the operations were completed within $1 \mathrm{~h}$ with a prompt correction of the defects. Results: Thirty-nine patients were satisfied with the treatment (93\%), while three had complications, local infection, and lumps, that were resolved quickly (7\%). Conclusion: Macrofillers can be injected into the calf to correct any defects. The advantages include short duration of treatment; the procedure performed under local anesthesia and limited side-effects that resolve promptly. This study suggests the use of biocompatible macrofillers for the augmentation of not only calves, but also for augmentation of breast and buttocks.
\end{abstract}

\section{Key words:}

Acid, augmentation, calves, hyaluronic, remodeling

\section{INTRODUCTION}

The use of fillers to improve cosmesis started in 1899 when silicone was used to improve the esthetic outcome of orchiectomy. Since then, numerous implants and filler substances have been used to reshape body defects. Permanent liquids and gels composed of silicone, paraffin, polyalkylimide, and polyacrylamide hydrogel have been used as fillers. ${ }^{\mid 1,2]}$ However, the incidence of chronic inflammatory reaction, palpable nodule formation, granuloma formation, and migration decreased the use of these materials. ${ }^{[1,3-5]}$ This led to the advent of new materials that are biocompatible and nonpermanent. In 2009, a new formulation of stabilized hyaluronic acid (HA)-based gel (NASHA-based gel; Q-Med AB, Uppsala, Sweden), was generated for restoring volume and contouring body surfaces. ${ }^{[3,6]}$ Since body augmentation requires a large volume of filler this formulation has increased viscosity (i.e. the

\begin{tabular}{|l|l|}
\hline \multicolumn{2}{|c|}{ Access this article online } \\
\hline Quick Response Code: & Website: \\
\hline & www.parjournal.net \\
\cline { 2 - 3 } & \\
\hline & \\
\hline
\end{tabular}

thicker gel) providing high resistance to deformation. HA gel augments body tissue simply by occupying space.

Calf augmentation with HA is often performed in patients who describe their calves as excessively tight (in extreme cases they may be described as "stork legs"). These patients often have insufficient muscular mass, fat atrophy, illness such as clubfoot, spastic paralysis, spina bifida, or poliomyelitis.

\section{METHODS}

Duration of procedures ranged from $30 \mathrm{~min}$ to $60 \mathrm{~min}$.

Materials used include:

- 20-120 mL of HA Blade number 15

- Sharp scissors

- Hudson forceps

- Small Kleimer

- $2.5 \times 150 \mathrm{~mm}, 12 \mathrm{G}$, filling cannula

- $3 \times 10 \mathrm{~mL}$ syringes

- $1 \times 100 \mathrm{~mL}$ bottle of physiologic solution

Anesthetic solution was prepared by mixing $6.4 \mathrm{~mL}$ of physiologic solution and $3.6 \mathrm{~mL}$ of mepivacaine (20 mg/mL) with adrenaline $(1 / 100,000)$.

A total of 42 cases of calf augmentations were performed at our office operating rooms under local anesthesia. The study was approved by review board of University of Turin. 
A photograph of the calf was taken before the treatment. After the first passage, it is necessary a pretreatment evaluation with the design on the skin of the interested area and this is an important passage because it's where anesthesia has got to be performed before the intervention. Later, $2.5 \mathrm{~mL}$ of preprepared local anesthesia mixture is injected into the subcutaneous space maintaining $2 \mathrm{~cm}$ apart between the injection points.

An 11 blade is used to make a small skin incision for insertion of cannula. Scissors are used to create a tunnel through the incision. Then, the cannula is inserted into the tunnel, and ultrasound guidance is used to navigate dissection through the subcutaneous space to reach the treatment area. The HA is delivered to the subcutaneous space through the cannula in a retrograde technique. Another tunnel is created through the same incision by changing the angle of the cannula [Figure 1]. This procedure is repeated until $\mathrm{HA}$ is uniformly filled in the desired location. A total amount of $30 \mathrm{~mL}$ of $\mathrm{HA}$ is delivered to each calf. Then, massage is performed and in the skin incision was closed with up with Vicryl 5-0 sutures [Figure 2]. Repeated treatments should be needed.

After the treatments, the patient had been asked to judge the results using a subjective evaluation scale in which they were asked to choose their grade of satisfaction between: very satisfied, satisfied, moderately satisfied, and unsatisfied.

\section{Anatomical pearls}

The great saphenous vein or the long saphenous vein is a large superficial vein that runs along medial side of leg

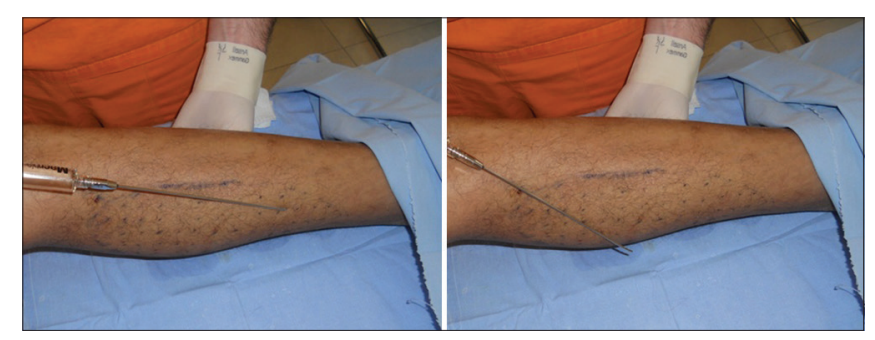

Figure 1: The $15 \mathrm{~cm}$ long cannula is used to inject hyaluronic acid subcutaneously into the calf

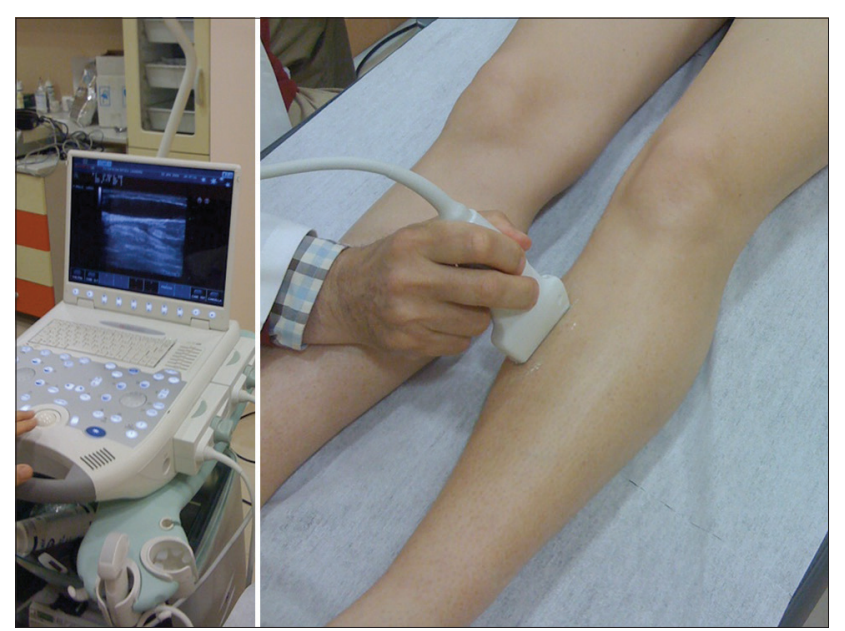

Figure 3: Ultrasound examination of tissues and vessels and thigh. The small saphenous vein is also a large vein that runs subcutaneously along posterior leg. Accidental injury to saphenous veins leads to noticeable hematomas and blood infarction of the implant with possible infection.

\section{Technical pearls [Figures 3-5]}

It is important to identify the saphenous vein using visual, tactile, and echographic examination to design the course of saphenous vein prior to injection.

In the subcutaneous space, the cannula should be directed superficial to superficial muscularis fascia of gastrocnemius in order to have a better management of the distribution of the filler and to avoid the rapid reabsorption of the material. The point and area of injection must be decided according to the defect that has got to be corrected.

\section{Complications}

Hyaluronic acid does not have tissue specificity and has minimal risk for allergic reactions when injected. However, the degree of complications increases when large volumes are injected. The complications are divided as early or late:

- Early complications are resolved in days to weeks after injection and include overcorrection, local infection, skin necrosis, herpes reactivation, discoloration, and

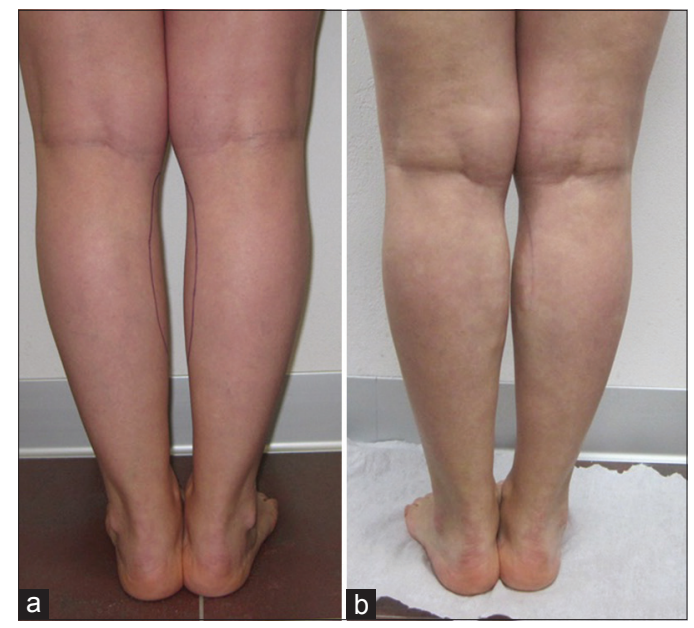

Figure 2: (a) Before, (b) after treatment

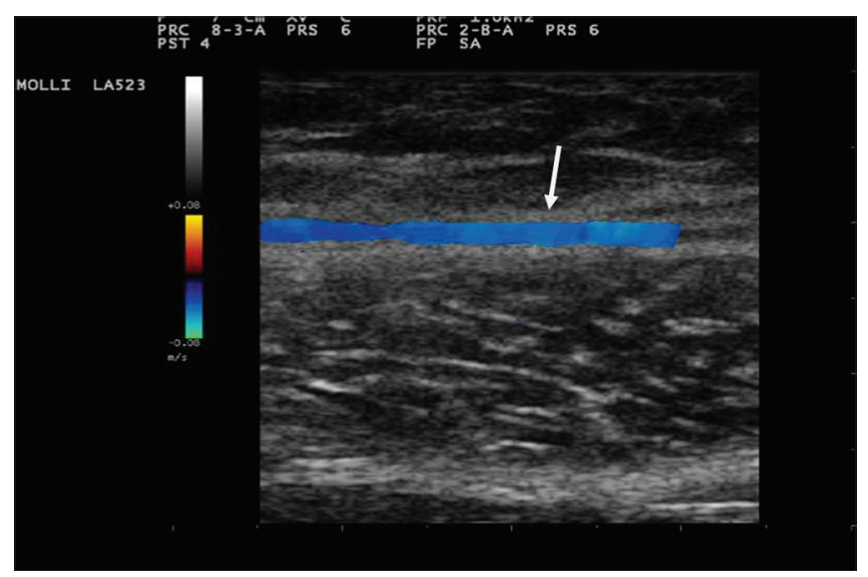

Figure 4: Ultrasound picture of the vein 


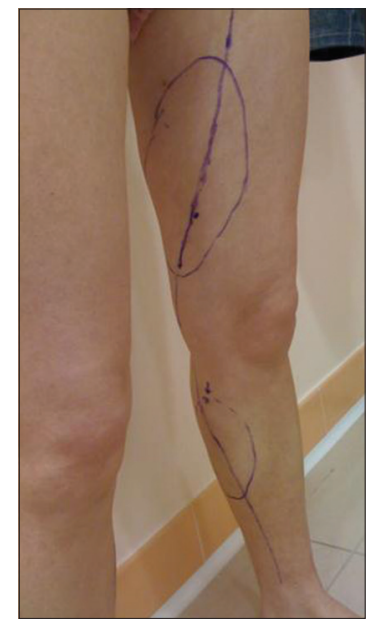

Figure 5: Outline of saphenous vein anatomy

persistent local symptoms (erythema, edema, induration, pruritus, and hyperpigmentation)

- Late complications include: infection, filler migration, delayed hypersensitivity reaction, foreign-body granuloma, and scarring. ${ }^{[7-10]}$

A case report in 2012 showed cellulitis of calf 5 days after injection of $150 \mathrm{~mL}$ of $\mathrm{HA}$ subcutaneously. This patient was treated with empiric antibiotic therapy (amoxicillin and clavulanic acid $1 \mathrm{~g}$ twice a day) with improvement of symptoms within $72 \mathrm{~h} .{ }^{[11]}$ This case shows that a serious complication can be resolved easily.

In this study, complications were seen in three cases. One patient developed local infection that resolved with oral antibiotics (amoxicillin and clavulanic acid).

Furthermore, we had two cases of lumps treated injecting hyaluronidase locally with consequent total reabsorption of the filler and correction of the defects.

\section{Contraindications}

Avoid injection of fillers in areas with poor perfusion or in areas of infection or inflammation.

Do not use macrofillers in areas that were previously treated with liquid silicone or other permanent fillers because it could lead to inflammation or infection of the implants.

It is contraindicated to use filler if patient has hypersensitivity to any components of the filler.

\section{DISCUSSION}

In patients who consider their calves as excessively tight, calf augmentation can be attained using HA fillers.
Overall, this study shows that patients have satisfactory results with this procedure. About $52 \%$ of patients were very satisfied, $24 \%$ of patients were satisfied, $10 \%$ of patients were moderately satisfied, and $14 \%$ were unsatisfied.

Furthermore, we have to underline that 8 patients (19\%) had no need to repeat the treatment, 34 patients $(81 \%)$ repeated the treatment once, and 23 patients $(54.7 \%$ ) repeated the treatment 2 times or more.

Fortunately only three complications occurred: one local infection resolved administering antibiotic and two lumps treated injecting hyaluronidase. In our study, we had no serious side effects unlike what happened to Chaput et al. that described a severe case of cellulitis. ${ }^{[11]}$

Our experience conducted over 42 cases suggests that the use of macrofillers, if compared with major surgery like the insertion of the silicon prosthesis, offers a better balance between efficacy and safety for good aesthetic results, because this technique is less invasive and also because of the low rate of side effects. These are the reasons why this technique should be taken in consideration especially in the case of remodeling and/or small augmentation of calves.

\section{REFERENCES}

I. Gómez-de la Fuente E, Alvarez-Fernández JG, Pinedo F, Naz E, Gamo R, Vicente-Martín FJ, Lopez-Estebaranz JL. Cutaneous adverse reaction to Bio-Alcamid implant. Actas Dermosifiliogr 2007;98:27I-5.

2. Klein AW, Elson ML. The history of substances for soft tissue augmentation. Dermatol Surg 2000;26:1096-105.

3. Hedén P, Sellman G, von Wachenfeldt M, Olenius M, Fagrell D. Body shaping and volume restoration: the role of hyaluronic acid. Aesthetic Plast Surg 2009;33:274-82.

4. McCleave MJ. Is breast augmentation using hyaluronic acid safe? Aesthetic Plast Surg 2010;34:65-8.

5. Broder KW, Cohen SR. An overview of permanent and semipermanent fillers. Plast Reconstr Surg 2006; I 8 (3 Suppl):7S- I 4.

6. Fumihiko I, Toshiya H, Kazuaki S. Hyaluronic acid breast augmentation. Jpn J Plast Reconstr Surg 2006;49:1335-4I.

7. Tezel A, Fredrickson GH. The science of hyaluronic acid dermal fillers. I Cosmet Laser Ther 2008; 10:35-42.

8. Lupo MP. Hyaluronic acid fillers in facial rejuvenation. Semin Cutan Med Surg 2006;25: 122-6.

9. Andre P. Hyaluronic acid and its use as a "rejuvenation" agent in cosmetic dermatology. Semin Cutan Med Surg 2004;23:218-22.

10. Winslow CP. The management of dermal filler complications. Facial Plast Surg 2009;25:124-8.

II. Chaput B, Eburdery H, Crouzet C, Grolleau JL, Chavoin JP, Garrido I. Macrolane ${ }^{\circledR}$ : a severe case of calf cellulitis after modeling injection. Ann Chir Plast Esthet 2012;57:83-6.

How to cite this article: Rosset L, Goisis M. Hyaluronic acid in calves defects correction. Plast Aesthet Res 2014;1:62-4.

Source of Support: Nil, Conflict of Interest: None declared.

Received: 28-03-2014; Accepted: 09-07-2014 